\title{
Estudo comparativo entre o laser endovenoso e a fleboextração convencional da veia safena interna em pacientes com varizes primárias
}

\author{
Comparison of endovenous laser therapy versus conventional stripping \\ of the great saphenous vein in patients with primary varicose veins
}

\section{Charles Angotti Furtado de M edeiros*}

Introdução: 0 diagnóstico de varizes écomum, sendo encontrado em até $25 \%$ das mulheres e $15 \%$ dos homens. T aispacientes procuram tratamento médico por várias razões, inclusive estética. 0 desenvolvimento de instrumentais mais apropriados e flexíveis, bem como a busca por técnicas menosinvasi vas com resultados aceitáveis, a curto elongo prazo, possibilitaram o aparecimento de novas modalidades terapêuticas.

O bjetivo: Comparar a fotocoagulação endovenosa com laser diodo de $810 \mathrm{~nm}$ ea fleboextração total da veia safena interna por meio de estudo prospectivo, analítico, do tipo ensaio clínico controlado e cego.

M étodos: 20 pacientes (40 membros inferiores) com varizes sintomáticas e insuficiência de veia safena interna bilateral pelo ultra-som Doppler foram operados no H ospital Estadual Sumaré, entremarço de2002 efevereiro de 2004. Para cada caso, sem o conhecimento dos pacientes, eram realizadas, aleatoriamente (sorteio), as duas técnicas, sendo uma em cada lado. A avaliação pósoperatória consistiu em consulta médica com a aplicação de questionários, exame físico e fotografia digital em todos os pacientes desde o sétimo pós-operatório (PO ). T ambém foi realizado mapeamento duplex no 30 PO e pletismografiaaar no 60 PO - por examinadoresúnicos, experientes e cegos aos dados. Este projeto foi aprovado sem restrições pela Comissão de Ética, e os pacientes foram incluídosao assinarem o consentimento pós-informação. T odos os dados foram submetidos à análise estatística com o programa SPSS.

R esultados: A técnica que utilizou o laser en dovenoso apresentou dor semelhante, mas menos edema $(P<0,05)$ emenos hematoma $(P<0,05)$ duranteo $P O .0$ índicede melhora estética e de satisfação com a cirurgia foi de $100 \%$, mas a maioria dos pacientes respondeu que 0 membro operado com o laser foi o mais beneficiado $(P<0,05)$. H ouve melhora hemodinâmica (tempo de enchimento venoso) nos dois grupos, mas sem diferença significativa. D urante o seguimento (média de nove meses), houve apenas um caso de parestesia levee transitória do lado convencional e somente uma recanalização do lado laser.

C onclusão: A fotocoagulação endovenosa para 0 tratamento da veia safena interna em pacientes com varizes de membros inferiores é segura e bem tolerada e apresenta resultados comparáveis aos da fleboextração convencional.

\footnotetext{
* Membro da Equipe do Centro de Referência em Cirurgia Endovascular, Universidade Estadual de Campinas (UNICAMP), Campinas, SP

Tese de mestrado apresentada à Pós-Graduação da Faculdade de Ciências Médicas, UNICAMP, Campinas, SP, para obtenção do título de Mestre em Cirurgia, área de Moléstias Vasculares Periféricas.

Orientador: Professor Livre-Docente Dr. George Carchedi Luccas

Apresentação: 22/02/2005

Banca examinadora: Prof. Dr. George Carchedi Luccas (FCM-UNICAMP), Prof. Dr. Fábio Hüsemann Menezes (FCM-UNICAMP), Prof. Dr. Miguel Francischelli Neto (Santa Casa de Limeira).

Correspondência: Charles Angotti Furtado de Medeiros, Rua Izabel Negrão Bertoti, 101/52, CEP 13087-671, Campinas, SP. Tel.: (19) 3256.9771, e-mail: drcharlesangotti@hotmail.com.

Resumo submetido em 06.12.05, aceito em 14.02.06.
} 